\title{
Victims' Dehumanization and the Alteration of Other-Oriented Empathy within the Immersive Video Milgram Obedience Experiment
}

\author{
Michaël Dambrun ${ }^{*}$, Johan Lepage ${ }^{2}$, Stéphanie Fayolle ${ }^{1}$ \\ ${ }^{1}$ Clermont Université, CNRS, Clermont-Ferrand, France \\ ${ }^{2}$ Université Pierre Mendès-France, Grenoble, France \\ Email: ${ }^{*}$ michael.dambrun@univ-bpclermont.fr
}

Received 22 September 2014; revised 18 October 2014; accepted 15 November 2014

Copyright (C) 2014 by authors and Scientific Research Publishing Inc.

This work is licensed under the Creative Commons Attribution International License (CC BY). http://creativecommons.org/licenses/by/4.0/

(c) (i) Open Access

\section{Abstract}

Using the Immersive Video Milgram Obedience Experiment (IVMOE; Dambrun \& Vatiné, 2010), we studied victims' dehumanization and its underlying processes. Under the supervision of the national service of security, participants were ordered to psychologically weaken a person suspected of preparing an attack. We manipulated the ethnicity of the victim and his terrorist membership. The doubly stigmatized victim (i.e. a North African victim member of al Qaeda) was tortured more severely than the other victims. We found some evidence that this effect was mediated by a decrease in term of other-oriented empathy, but not by personal distress. These results suggest that an empathy alteration process underlies dehumanization in crimes of obedience perpetrated against members of extreme out-groups.

\section{Keywords}

Dehumanization, Empathy, IVMOE, Torture, Crime of Obedience

\section{Introduction}

Crimes of obedience are a central phenomenon in social sciences (Kelman \& Hamilton, 1989). The first decade of the $21^{\text {st }}$ century witnessed an increase of interest for the issue of torture. This renewed attention could be attributed, to some extent, to the abuse of Iraqi prisoners by US soldiers at Abu Ghraib in the spring of 2004.

\footnotetext{
${ }^{*}$ Corresponding author.
}

How to cite this paper: Dambrun, M., Lepage, J., \& Fayolle, S. (2014). Victims' Dehumanization and the Alteration of OtherOriented Empathy within the Immersive Video Milgram Obedience Experiment. Psychology, 5, 1941-1953. 
Dramatically, investigations on frequency of torture practices outside Abu Ghraib revealed that: "the US military's extralegal use of aggression, violence, and torture was not isolated-it was systematic” (Lankford, 2009: p. 389). More broadly, despite the absolute prohibition of torture and the fact that the UN Convention has been ratified by 147 states, torture is still routinely practiced in many parts of the world. Because Human right violations keep repeating themselves over the years, it is important to place greater attention on measures of prevention in order to guarantee non-repetition. Such an ambition requires scientific investigations of the social psychological processes which make crimes of obedience possible.

Despite its importance as a social and scientific issue, the empirical study of destructive obedience has been relatively neglected (see Waller, 2002). The pioneering research of Milgram (1974) remains the seminal reference. As noted by Lankford (2009): "the dehumanization of targets is often cited as a key factor which enables the ruthless violation of those outside the system" (see also Bandura, 1999; Baumeister, 1997; Johnson, 1986, 1998; Kelman, 2001, 2005; Kelman \& Hamilton, 1989; Waller, 2002). Research on dehumanization suggests that group acting outside societal norms would be dehumanized (Bar-Tal, 1989). Consistently, Kelman (2005) claimed that the main cause of the torture victims' dehumanization is their designation as a threat, and that a contributing factor is that they are often members of an ethnic stigmatized out-group. If dehumanization is believed to be a key factor in destructive obedience, no previous research has tested this assumption using a paradigm of obedience to authority. The present study fills this gap in the literature. Thus, we manipulated two key variables: the victim's ethnicity and the belonging to a threatened group. Because the experimental approach of destructive obedience involves considerable ethical challenges and starting with the idea that Immersive Virtual Environment Technology (IVET; see Blascovich et al., 2002) is a useful tool to study social behavior, we investigated the role of these variables using our Immersive Video Milgram Obedience Experiment (IVMOE; Dambrun \& Vatiné, 2010). Because we were also interested in the underlying processes of dehumanization, we investigated the respective role of personal distress and other-oriented empathy.

\subsection{Immersive Environment and Embodiment Processes}

Recently, using an immersive virtual environmental technology (IVET; see Blascovich et al., 2002), several researchers independently developed new paradigms for studying obedience to authority in an ethical manner (see Cheetham, Pedroni, Antley, Slater, \& Jäncke, 2009; Dambrun \& Vatiné, 2010; Slater, Antley, Davison, Swapp, Guger, Barker, et al., 2006). Slater et al. (2006) developed a similar paradigm to the Milgram's one using IVET in order to investigate human responses to interaction with a virtual human in an extreme social situation, and found that participants responded to the situation at the subjective, behavioral and physiological levels as if the victim and the shocks were real (see also Cheetham et al., 2009).

The paradigm developed by Dambrun \& Vatiné (2010), called the IVMOE (Immersive Video Milgram Obedience Experiment), is a similar immersive paradigm with some important differences. Indeed, in order to ensure a high level of realism and ecological validity, the victim is not a virtual person, but a real person filmed, recorded, and displayed on a computer screen. Moreover, this paradigm consists in an exact replication of the Milgram experiment and all parameters are computer-programmed in order to give the impression of real time and a dynamic environment. Dambrun \& Vatiné (2010) tested the psychometric validity of the IVMOE by attempting to replicate the main findings of Milgram experiments and succeeded in demonstrating that immersive environment is a useful tool to study obedience to authority. The fact that participants' cognitions, emotions, and behaviors within immersive environment were similar to those observed in real environments is consistent with embodiment theory proposing that "perceiving and thinking about emotion involve perceptual, somatovisceral, and motoric re-experiencing (collectively referred to as 'embodiment') of the relevant emotion in one's self." (Niedenthal, 2007: p. 1002). Thus, the participants re-experienced the victim's pain and distress and felt anguish and conflict in delivering electric shocks.

\subsection{The Role of the Victim's Ethnicity within the IVMOE}

Importantly, Dambrun \& Vatiné (2010) manipulated the victim’s ethnicity and found that participants reported less anxiety and distress when the victim was a North African (a stigmatized out-group) than when the victim was of the same ethnic origin as the participant (i.e. French). This result is consistent with studies showing that individuals are more "sensitive" to in-group members' emotions and feelings than to those of an out-group (e.g. Chambon, Droit-Volet, \& Niedenthal, 2008; Elfenbein \& Ambady, 2002; Mondillon, Niedenthal, \& Droit-Volet, 
2007), and was interpreted as an early process of racial dehumanization. However, because North Africans are a prime target of prejudice in France, it remains unclear if this result was due to mere racial categorization or to racial stigmatization. It is possible that negative feelings toward North Africans contribute to the alteration of the empathic resonance. Consistently with this hypothesis, Dambrun (2007) found that racial prejudice against North Africans, but not against non-stigmatized out-groups, was a main predictor of support for the death penalty in France. In order to test the respective contribution of both mere racial categorization and racial stigmatization on how the participants experience the negative emotions of the victim, first we added to the present study a non-stigmatized ethnic target: a group of Spaniards (e.g. Guimond, 2010). Thus, participants were randomly exposed to an in-group member victim (same racial origin; i.e. French), a non-stigmatized out-group member victim (i.e. Spanish) or a stigmatized out-group member (i.e. North African).

In addition, it is important to note that Dambrun \& Vatiné (2010) did not found any significant effect of victim's ethnicity on obedience to authority; the participants delivered a similar amount of electric shocks to both the North African and the French victim. Several theoretical perspectives suggest that such a racial categorization is not sufficient to produce destructive obedience behaviors. The belonging to an extreme out-group eliciting disgust appears to be a necessary condition for dehumanization to occur.

\subsection{Dehumanization of the Victim and Extreme Out-Group Membership}

Dehumanization of the targets appears as a key factor in destructive obedience. As noted by Lankford (2009): "dehumanizing the targets of violence helps aggressors feel like their actions are much less morally significant. The otherwise natural sympathy and empathy for the victim is reduced because of the contrived distinction between the in-group — which is human —and the out-group—which is something less” (p. 394). According to Kelman (2005), the justification of torture "as a means of protecting the state against threats to its security helps to authorize the practice; the development of a profession of torturers as part of the state's security apparatus helps to routinize the administration of torture; and the designation of the targets of torture as enemies of the state who are excluded from the state's protection helps to dehumanize the victims” (Kelman, 2005: p. 16).

The legitimacy perspective (Kelman, 2001, 2005; Kelman \& Hamilton, 1989) proposes that dehumanization is the consequence of a broader process of delegitimization. Delegitimization refers to a process of recategorization out of the domain of moral acceptability and moral obligations (Kelman, 2001; Oren \& Bar-Tal, 2006). This process excludes the targets from "the boundary in which moral values, rules, and considerations of fairness apply. Those who are morally excluded are perceived as non-entities, expendable, or undeserving; consequently, harming them appears acceptable, appropriate, or just'” (Opotow, 1990: p. 1). The social function of such a victims' exclusion from the perpetrators' moral community should be to justify violence by attributing its cause to the victims' nature or characteristics. Out-casting (categorizing individuals or groups as a social threat) and dehumanization (denying some fundamental human characteristics to an out-group) are the two most commonly used component of delegitimization (Kelman, 2005; Oren \& Bar-Tal, 2006). Groups acting outside societal norms and being perceived as a social threat would be dehumanized (Bar-Tal, 1989; Kelman, 2005). Consistently, the Stereotype Content Model (SCM; Fiske, Cuddy, Glick, \& Xu, 2002) also predicts that perceived moral violations lead to dehumanization.

The Stereotype Content Model (SCM) differentiates out-groups into four Warmth (intending either help or harm) $\times$ Competence (capable or not of enacting those intentions) clusters, and posits that the four combinations of these dimensions produce four distinct emotions toward social groups: pride, envy, pity and disgust. The disgust is unique among these emotions because it can target either humans or nonhumans, making people functionally equivalent to objects (Harris \& Fiske, 2006). Thus, Harris \& Fiske (2006) conducted a fMRI research with the hypothesis that only a disgust-evoking low-low quadrant (groups that are both stereotypically hostile and stereotypically incompetent) would generate dehumanizing prejudice. As expected, the results revealed that only low-low out-groups (e.g., drugs addicts) were associated with the same neural activations than disgusting objects (e.g., vomits), that is an activation of amygdala (fear) and insula (disgust), and an absence of the typical neural signature for social cognition (i.e., activation of the medial prefrontal cortex-mPFC). These results are consistent with other findings showing that not just any out-group is dehumanized. For example, the same authors found significant mPFC activity in White participants watching Black faces (Harris \& Fiske, 2003; see also Wheeler \& Fiske, 2005).

Following these perspectives, in addition to the victim's ethnicity, we manipulated a new variable in the study 
of destructive obedience: belonging or not belonging to a known terrorist group that generates threats (i.e. al Qaeda; e.g. Echebarria-Echabe \& Fernández-Guede, 2006; Hitlan, Carrillo, Zarate, \& Aikman, 2007). We predicted that only the doubly stigmatized victim (North African belonging to a terrorist group) would be more severely torture than the others.

\subsection{Personal Distress and Other-Oriented Empathy as Underlying Processes}

Another relevant issue concerns the identification of the psychological underpinnings of dehumanization. We argue that victims' dehumanization process should affect destructive obedience by impairing the individuals' ability to process the victims' pain and distress. Empathy is an essential component of moral thought and of motivation to perform prosocial or helping behaviors (e.g., Batson et al., 1991; Decety \& Jackson, 2004). However, the relationship between empathy and prosocial behaviors is complex. Recent social neuroscience research exploring how people respond behaviorally and neurally to the pain of others demonstrates that the mere perception of another individual in pain results, among the observer, in the activation of the neural network involved in the processing of firsthand experience of pain (Decety \& Jackson, 2004). Pain affect sharing can lead to sympathy (i.e. concern for other) or to personal distress (i.e. aversive, self-focused emotional reaction; Decety \& Lamm, 2009). Empathic concern promotes moral reasoning and altruism (Batson et al., 1991), whereas personal distress is associated with the desire to alleviate one's own but not the other's distress (Batson, 1991). Consistently, Burger (2009) conducted a partial replication of Milgram paradigm and found some evidence that individual differences in other-oriented empathy affected participant's level of obedience. In another partial replication, Zeigler-Hill, Southard, Archer and Donohoe (2013) found that the individuals who where the most reluctant to obey reported the highest levels of negative affect during the session.

According to Decety \& Jackson (2004), three main processes are involved in empathy: 1) affective sharing between the self and the other; 2) self-other awareness; 3) mental flexibility and self-regulation. Mental flexibility and self-regulation permit to conscientiously engaging in perspective taking and maintaining conscious engagement in perspective taking, and maintenance of clear self-other distinction (Decety \& Lamm, 2009). If these conditions are not satisfied, people are expected to experience over-arousal and then personal distress (Eisenberg, Valiente \& Champion, 2004). However, mental flexibility and self-regulation constitute an effortful self-regulatory process. Effortful control has been correlated with high sympathy or empathy and low personal distress (Eisenberg et al., 1996). Thus, empathy and sympathy require the motivation to comprehend the others' state (Eisenberg \& Eggum, 2009).

Recent studies revealed that empathy is a highly flexible phenomenon and that empathic resonance is moderated early in information processing by how observers conceptualize both the situation and the person who is expressing pain (Singer \& Lamm, 2009). For example, Decety, Echols, \& Correll (2010) found that the stigmatized target in a state of suffering generated both less personal distress, and also less empathic concern (see also Xu, Zuo, Wang, \& Han, 2009). Thus, both bottom-up and top-down processes of empathy are influenced by targets' identities. Research on infra-humanization (Leyens et al., 2001, 2003) demonstrates that dehumanized groups are believed not to experience complex human emotions. Thus, dehumanization could impair the belief that the victim can have complex human emotions and then impair both pain affect sharing and effortful selfregulatory process. In support for our purpose, in a recent meta-analysis, Pettigrew \& Tropp (2008) reported a robust and negative relationship between other-oriented empathy and prejudice. Schechtman \& Basheer (2005) revealed that other-oriented empathy was negatively correlated to beliefs supporting aggression among a sample of Arab children in Israel.

In view of the existing literature, it is likely that other-oriented empathy and personal distress play a central role in the regulation of violent behaviors perpetrated against an extremely stigmatized out-group member such as a North African member of al Qaeda. This stigmatization would alter pain affect sharing and effortful selfregulation, resulting in more aggressive behaviors against the victim. Because little researches have examined the relationship between empathy and such behaviors using an experimental paradigm, we examine the respective contributions of personal distress and other-oriented empathy in the causal relation between dehumanization and obedience to authority within an immersive environment.

\subsection{Summary and Overview of the Current Study}

\subsubsection{Cover Story}

As noted by Kelman (2005), torture operates on the assumption that the targets are individuals "who have com- 
mitted and/or are about to commit dangerous crimes against the state. Thus, torture is designed only to punish the guilty, to warn their accomplices, and-most important—-to elicit the truth from them. Indeed, torture is often justified on the grounds that it is the only way to elicit information necessary for the protection of the state and its citizens” (p. 21). Thus, participants were informed that they would participate as citizens' party to an interrogation under the supervision of the national security service. Their role was to psychologically weaken a suspect for subsequent interrogation. Because in violent conflicts ordinary citizens are often recruited to accomplish acts of torture and murder, such a situation is very closed to reality. By enhancing the ecological validity of the paradigm, we also expected to reduce the disturbing element sometimes observed in the classic paradigm in which participants find the situation unreal, absurd, and very ambiguous (Greenwood, 1989).

\subsubsection{Hypotheses}

We manipulated the victim's ethnicity (French, Spanish, or North African) and the belonging to a network (al Qaeda or Association Football), and we predicted that only the double stigmatized victim (i.e., North African and terrorist) would be dehumanized and then would received harsher treatment. Moreover, we predicted that participants would experience less personal distress and other-oriented empathy in the presence of an extreme out-group member victim than in the other conditions. More precisely, we expected that the relationship between double stigmatization and obedience should be mediated by a decrease of other-oriented empathy and by a decrease of personal distress.

\section{Method}

\subsection{Participants}

One hundred and twenty-four undergraduates from Blaise Pascal University (France) took part in the study. Five participants of North African origin were not included in the analyses. The remaining sample was constituted of 119 participants of French origin (100 women; $M$ age $=19.2, S D=1.34$ ). Our study was subject to full ethical scrutiny with no deception, informed written consent, and full debriefing.

\subsection{Procedure and Materials}

The IVMOE-I. As depicted in Figure 1, the IVMOE-I was controlled by Psyscope X on an Apple Macintosh OS $\mathrm{X}$ equipped with a video projector (screen size $2 \mathrm{~m} \times 1 \mathrm{~m} \mathrm{20}$ ). The distance between the participant and the screen was approximately 2.50 meters.

The IVMOE-I is very similar to the IVMOE (i.e. Improved IVMOE) (Dambrun \& Vatiné, 2010) except that the cover story is entirely different. On the first slide, it was made explicit that both the shocks and the victim's

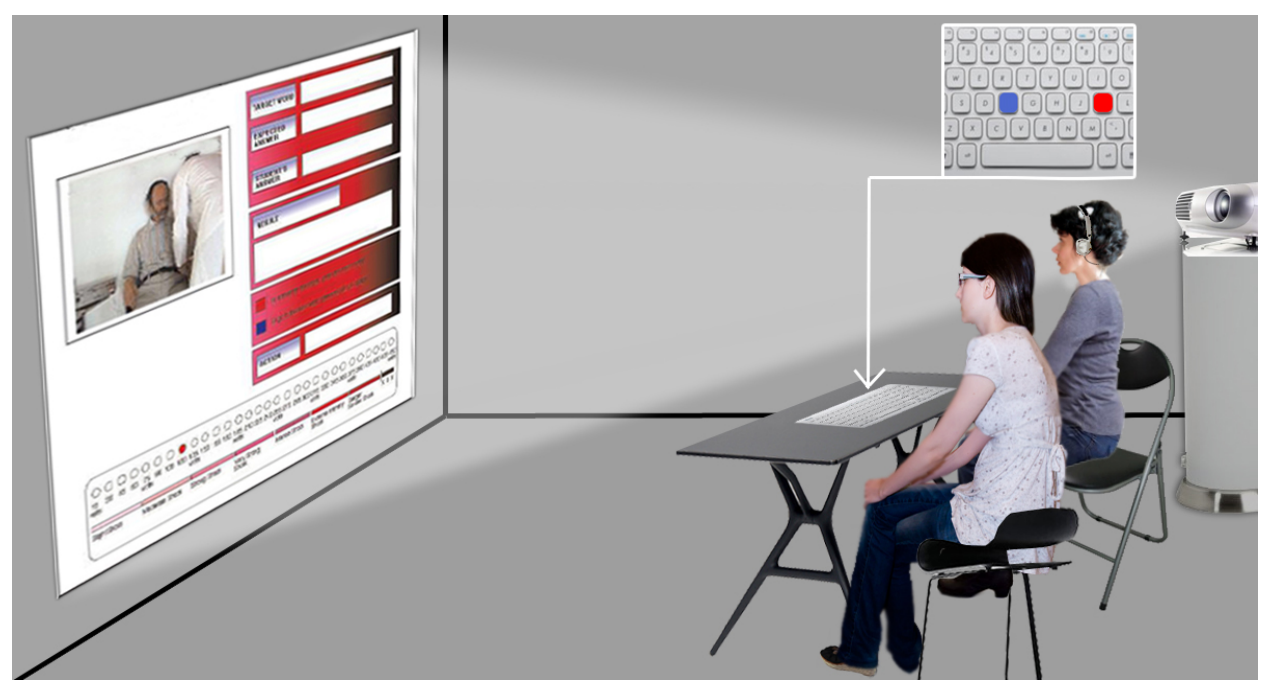

Figure 1. The projection of the IVMOE-I on a wall screen with the participant on the right (headphones on) and the experimenter on the left. 
reactions were not real but simulated. The IVMOE-I was structured in three parts: the explanation and instruction phase (step 1), the memorization of the suspect's record (step 2), and the experimental task (administration of the punishments; step 3). During the instruction phase, participants were informed that they would participate as citizens' party to an interrogation under the supervision of the national security service. It was explained that this would take place in two stages. The first stage consisted of psychologically weakening the suspect in order to facilitate his cooperation during the interrogation. They were informed that another person would conduct the interrogation phase and that they were responsible for conducting the phase of psychological weakening.

During the second part, the security service ordered the participants to inspect the suspect's record and familiarize themselves with it. This file included a variety of information. Ethnicity (French, Spanish, or North African) and belonging to a network (al Qaeda or Association Football) were experimentally manipulated. Finally, participants were asked to proceed to the phase of psychological weakening. First, they were informed that this phase consisted of a paired-associate learning task (15 pairs) in which the suspect had to indicate for each pair which of four words had originally been paired with the first word. They were informed that, to encourage errors on the part of the suspect, the words were intentionally chosen to be very difficult to memorize. They were instructed to punish each error with an electric shock (red key). At this point, the procedure was similar to that of the IVMOE (Dambrun \& Vatiné, 2010). To prevent unnecessary stress, however, the number of shocks was reduced (i.e. 10 shocks instead of 30 with a 30-volt increment). All participants finished on a correct answer from the victim.

As was the case in the original experiment, the primary dependent variable was the maximum shock administered before the participant refused to go any further. The score could vary from zero (for a participant who refused to administer even the lowest shock) to 300 (for a participant who administered the highest shock). Two extreme values were identified and excluded from the analyses ${ }^{1}$ ( $1.68 \%$ of the total sample).

\subsection{Questionnaire Measures}

Personal distress. The French version of the State Anxiety Inventory developed by Spielberger, Gorsuch, \& Luchene (1970), was used. By means of a visual analogue rating scale anxiety was assessed twice: before the IVMOE-I $(\alpha=0.92)$ and just after $(\alpha=0.93)$. We computed the difference score. Higher scores indicated an increase in anxiety between time 1 and time 2. The Peri-traumatic Distress Inventory (Brunet, Weiss, Metzler, Best, Nylan, \& Rgers, 2001) also was assessed. This scale provided an adequate reliability ( $\alpha=0.82)$. One extreme value was excluded from the analyses ${ }^{1}(0.84 \%$ of the total sample). Higher scores on this scale indicated greater peri-traumatic distress.

Other-oriented empathy. At the end of the IVMOE-I, participants were asked to complete a modified version of Davis's (1983) empathy scale. The items of this scale have a fairly general content. Whenever possible, we adapted them to the context of the IVMOE-I (e.g. "I felt sorry for the suspect"; "Before sending an electric shock, I tried to imagine how I would feel if I was in his place”). For the eleven items that we adapted, a reliability analysis indicated that two were deviant (item-total correlation $<0.10$ ). Thus, they were excluded. This nine-item scale showed satisfactory reliability $(\alpha=0.81$ ). Higher scores on this scale indicated greater otheroriented empathy.

\section{Results}

\subsection{Obedience to Authority}

Mean maximum voltage level. We tested in an ANOVA the effect of our independent variables as well as the interaction term. The results are depicted in Figure 2. The effect of victim's ethnicity was marginally significant $\left(F(2,117)=2.58, p<0.08, \eta^{2}<0.044\right)$. The mean maximum voltage level was significantly higher when the victim was North African $(M=259.46)$ than when she was French $(M=225.75)$ or Spanish $(M=213.0 ; p<$ $0.04)$. The difference between the French victim $(M=225.75)$ and the North African one was not statistically significant $(p=0.13)$. Neither the effect of terrorist membership $\left(F(1,117)<1, p<0.32, \eta^{2}<0.01\right)$, nor the in-

\footnotetext{
${ }^{1}$ Because the presence of extreme outliers favors both Type I and Type II errors, their removal has a strong beneficial effect (see Osborne \& Overbay, 2004), especially on sensitive topics such as the one of this study (e.g. outliers from intentional or motivated mis-reporting). Thus, prior to the analyses, extreme outliers were identified in a rigorous statistical procedure and were systematically excluded from the analyses. To identify extreme outliers, an explore analysis by experimental conditions was conducted on SPSS. Extreme outliers were any score more than $3 *$ IQR (InterQuartile Range) from the rest of the scores.
} 
teraction between victim's ethnicity and terrorist membership $\left(F(2,117)=1.57, p<0.21, \eta^{2}<0.03\right)$ was statistically significant. We tested our specific hypothesis using a contrast (see Table 1 ) in a regression analysis. Using the double stigmatization contrast, the analysis revealed a significant effect $(\beta=0.23, p<0.02)$. The doubly stigmatized victim $(M=285.9)$ received more punishment than the victim of the other conditions $(M=222.9)$.

Percentage of obedience. Using binary logistic regression analyses with the binary scores of obedience as a dependent variable ( 0 . not fully obedient; 1 . fully obedient), neither the effect of victim's ethnicity $(b=0.36$, $S E=0.24, p<0.14)$, nor the effect of terrorist membership $(b=.18, S E=.20, p<0.37)$ or the interaction effect $(b=0.36, S E=0.24, p<0.14)$ was statistically significant. We tested our specific hypotheses using thesame contrast (see Table 1 ). The double stigmatization contrast was marginally significant $(b=0.22, S E=0.11, p=$ 0.052). Participants were more inclined to fully obey when the victim was doubly stigmatized $(82.4 \%)$ than in the other conditions (56\%).

\subsection{Personal Distress}

State-anxiety. Using the anxiety scores at time 1 (before the IVMOE-I) and at time 2 (after the IVMOE-I), we tested in a mixed analysis of variance the effect of our independent variables as well as the interaction term. Participants were significantly more anxious at time $2(M=3.15)$ than at time $1(M=1.82 ; F(1,113)<100.12, p<$ $\left.0.001, \eta^{2}=0.47\right)$. No other effect, including the contrast, was significant. State anxiety and the mean maximum voltage level were not significantly correlated $(r=-0.12, p<0.21)$.

Peri-traumatic distress. We tested in an ANOVA the effect of our independent variables as well as the interaction term. This analysis did not reveal any significant effect. However, again only the doubly stigmatization contrast was significant $(\beta=-0.21, p<0.02)$. The results are depicted in Figure 3. Participants who were exposed to a double stigma $(M=0.81)$ reported a significant lower level of peri-traumatic distress than those of the other conditions $(M=1.20)$. Peri-traumatic distress and the mean maximum voltage level were not significantly correlated $(r=-0.07, p<0.44)$.

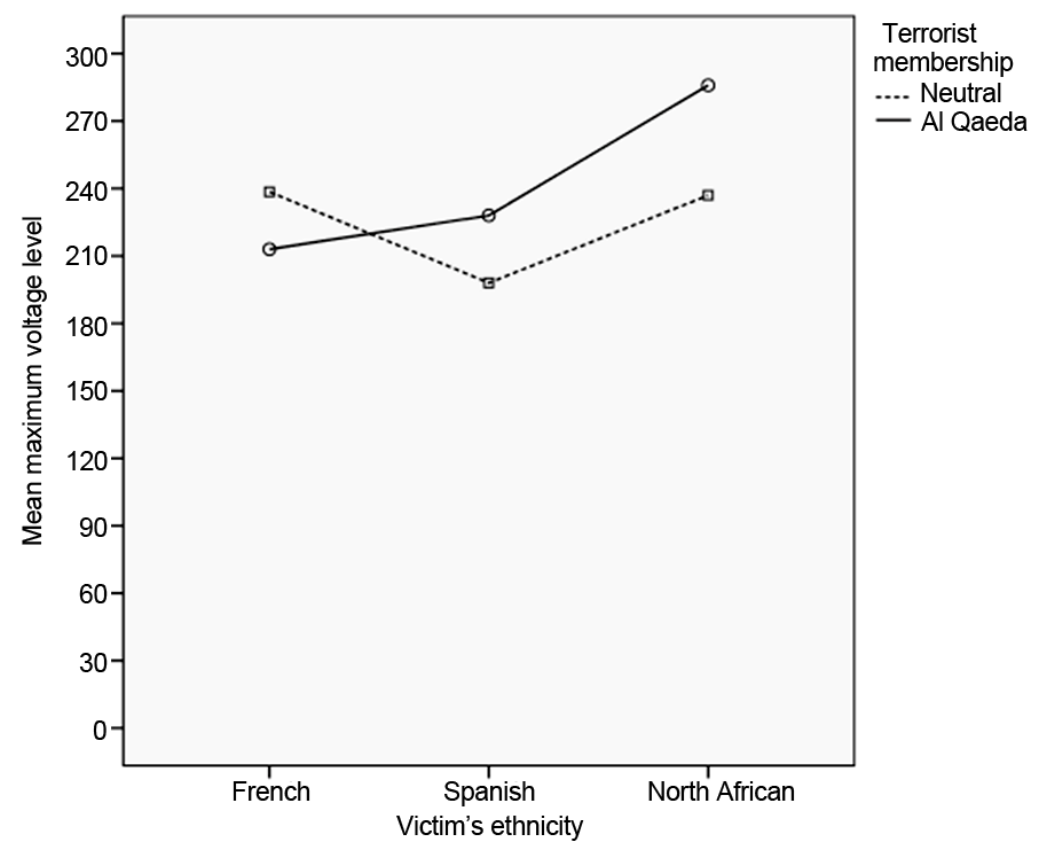

Figure 2. Mean maximum voltage level as a function of victim's ethnicity and terrorism membership.

Table 1. Contrast used in the statistical analyses.

\begin{tabular}{lcccccc}
\hline & \multicolumn{2}{c}{ French } & \multicolumn{2}{c}{ Spanish } & \multicolumn{2}{c}{ North African } \\
\hline & Neutral & Terrorist & Neutral & Terrorist & Neutral & Terrorist \\
Double Stigmatization Contrast & -1 & -1 & -1 & -1 & -1 & +5 \\
\hline
\end{tabular}




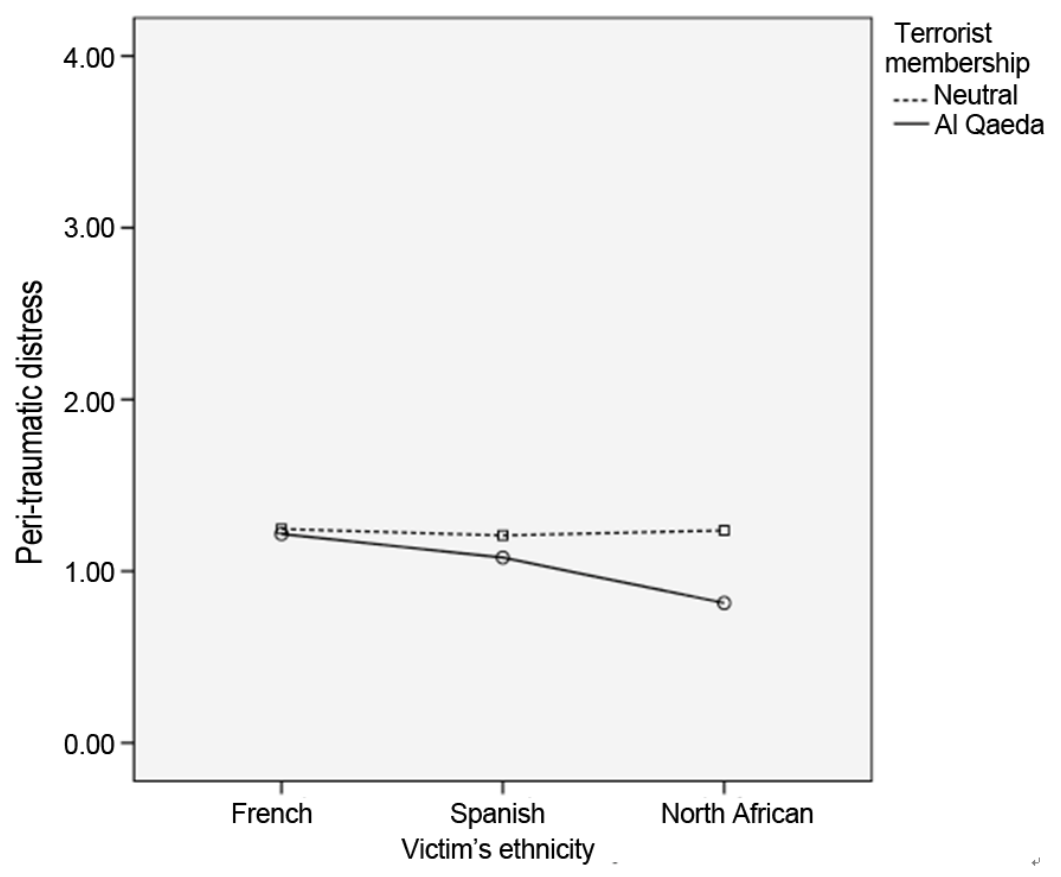

Figure 3. Peri-traumatic distress as a function of victim's ethnicity and terrorism membership.

\subsection{Other-Oriented Empathy}

Using the scale of other-oriented empathy as a dependent variable, we conducted ANOVA. The effect of victim's ethnicity was not significant $\left(F(2,119)=1.93, p<0.15, \eta^{2}=0.033\right)$. The effect of terrorist membership was marginally significant $\left(F(1,119)=3.11, p<0.08, \eta^{2}=0.03\right)$. This effect revealed that participants expressed greater empathy for the non-terrorist member $(M=4.43)$ than for the member of al Qaeda $(M=4.08)$. The interaction between victim's ethnicity and terrorist membership was not significant $(F<1)$. Finally, the doubly stigmatization contrast was statistically significant $(\beta=-0.21, p<0.03)$. The results are depicted in Figure 4. Participants expressed significantly less empathy for the doubly stigmatized victim $(M=3.73)$ than for the others $(M=4.36)$. Other-oriented empathy and the mean maximum voltage level were significantly related $(r=-0.30, p<0.001)$.

\subsection{Mediation Analyses}

We tested the extent to which other-oriented empathy mediated the effect of double stigmatization on the mean maximum voltage level. As previously mentioned the IV (double stigmatization), the DV (the mean maximum voltage level) and the mediator (other-oriented empathy) were significantly related. Thus, we followed the procedure advocated by Preacher \& Hayes (2004); (5000 samples and confidence intervals $=95 \%$ ). When empathy was statistically controlled for, the double stigmatization effect on the mean maximum voltage level became non-significant ( $\beta=0.17, p<0.06$ ). But, the effect of other-oriented empathy on the mean maximum voltage level remained significant even when double stigmatization was statistically controlled $(\beta=-0.26, p<0.01)$. The $z$-test, performed to test the significance of the mediation, was marginally significant $(z=1.79, p<0.08$; see Figure 5(a)), and $25.44 \%$ of the effect of double stigmatization on the mean maximum voltage level was mediated by other-oriented empathy, indicating a partial mediation. We found similar support for the reversed model in which the mean maximum voltage level mediates the effect of double stigmatization on other-oriented empathy (see Figure 5(b)). Specifically, when the mean maximum voltage level was controlled for, the effect of double stigmatization on other-oriented empathy became non-significant $(\beta=-0.16, p<0.08)$. But the effect of other-oriented empathy on the mean maximum voltage level remained significant even when stigmatization was statistically controlled ( $\beta=-0.26, p<0.01)$. The $z$-test was marginally significant $(z=1.84, p<0.07)$, and $22.82 \%$ of the effect of stigmatization on other-oriented empathy was mediated by the mean maximum voltage level, indicating a partial mediation. 


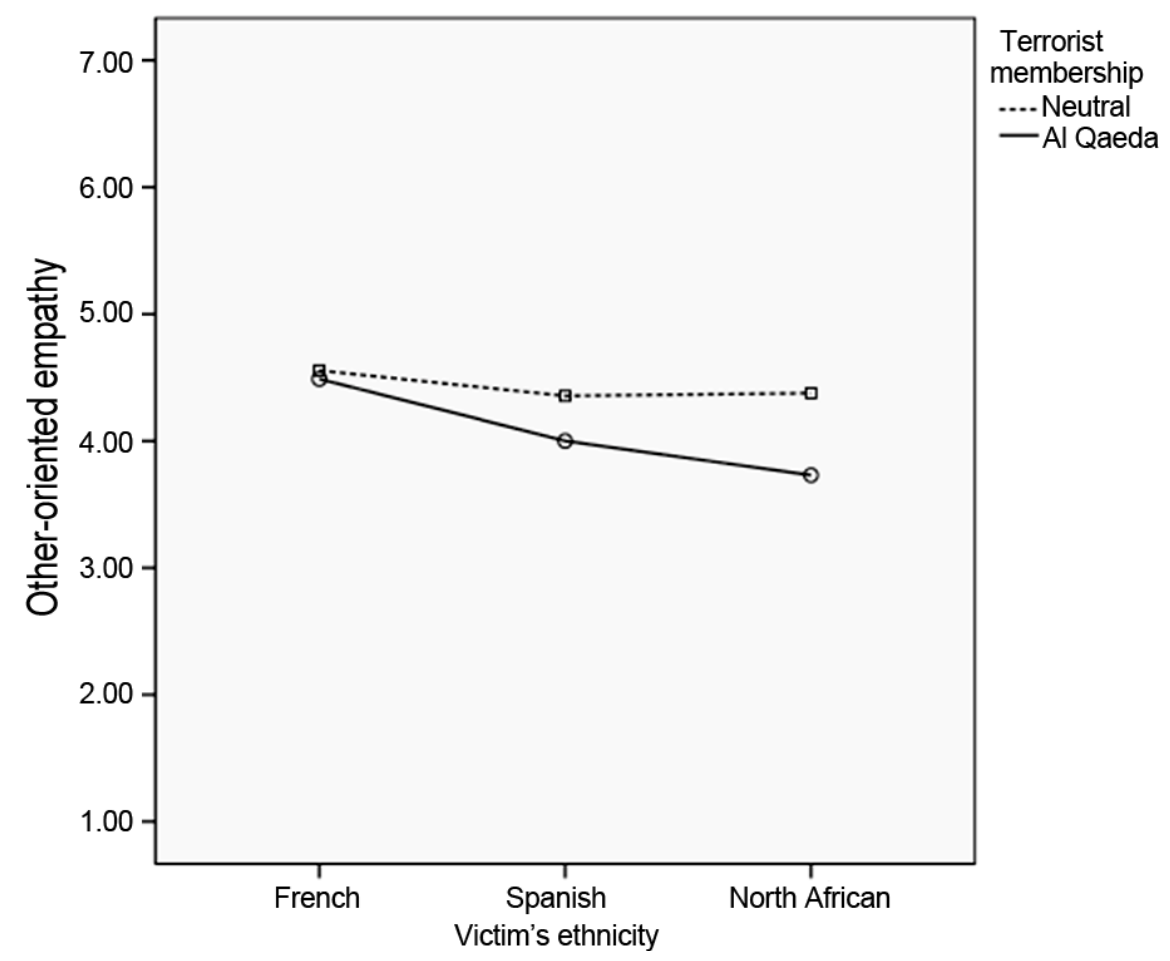

Figure 4. Other-oriented empathy as a function of victim's ethnicity and terrorism membership.

a): Predicted Model

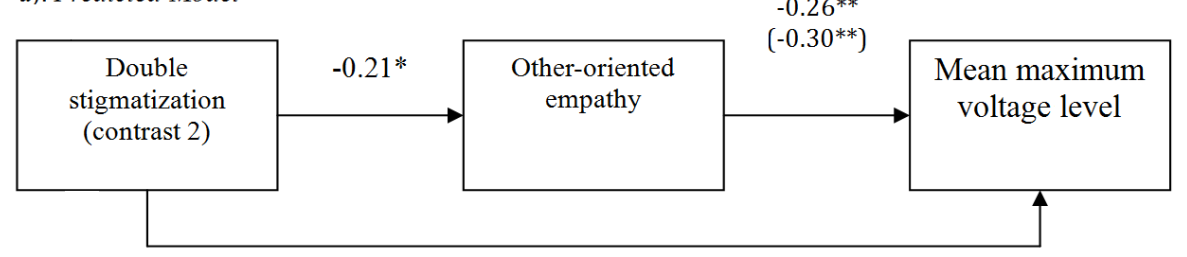

$0.17+\left(0.23^{*}\right)$

b): Reversed Model

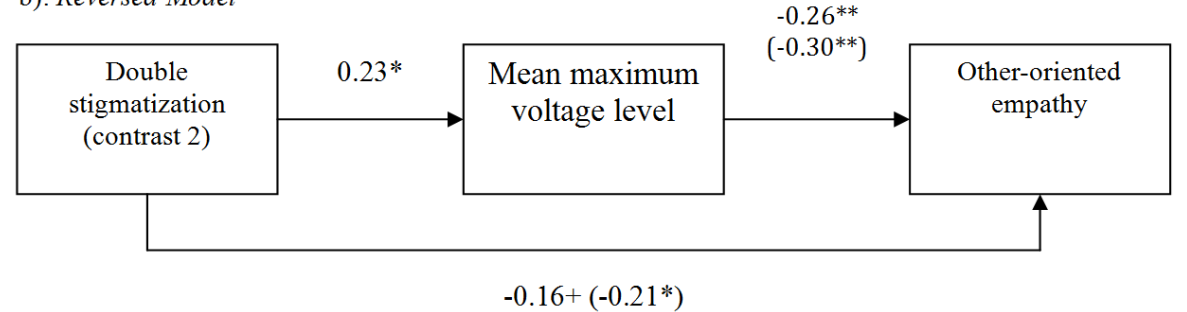

Figure 5. Mediation model: Other-oriented empathy as a mediator of the effect of double stigmatization (contrast 2) on the mean maximum voltage level.

\section{Discussion}

\subsection{Contribution of the Current Investigation}

Regarding the understanding of crimes of obedience, our work adduces some new insights. The victim who received the most severe treatment was the one who belonged to a (doubly) stigmatized group. Mere racial categorization is apparently not sufficient to generate differential treatment of the victim. More specifically, while the condition in which the victim was stigmatized on a single dimension (i.e. North African OR Terrorist) did not 
differ from the condition in which the victim was non-stigmatized, the presence of a double stigma significantly increased the amount of punishment administrated to the victim. In the context of organized torture by a national service of security, the racial stigma and the terrorist stigma (i.e. belonging to a threatened group) were additive and together lead to more severe torture of the victim. Thus, torture was not generalized to any stigmatized outgroup members; only a "disgust-evoking low-low quadrant" increased destructive obedience. This is consistent with several important approaches, such as the Stereotype Content Model and the legitimacy perspective. It is worth noting that these conditions match perfectly with those of Guantanamo where the victims of torture were at the same time suspected to belong to a threatening terrorist group and also member of a stigmatized racial outgroup (Arab). While some social psychological analyses of the Guantanamo issue have been recently provided (see for example Fiske, Harris, \& Cuddy, 2004), to our knowledge, this study is the first to provide a direct empirical analysis of dehumanization within an obedience paradigm.

Second, this study also provides some new elements concerning the underlying processes leading the participants to punish more severely the doubly stigmatized victim. As expected, participants reported a lower level of personal distress (i.e. peri-traumatic distress) and a lower level of other-oriented empathy when the victim was doubly stigmatized than when she was stigmatized on a single dimension or non-stigmatized. This effect reveals that participants exhibited less anguish and conflict in delivering dangerous shocks to the doubly stigmatized victim than to the others. However, personal distress and other-oriented empathy does not play a similar role. We found some support for a mediation model in which other-oriented empathy mediates, at least partially, the effect of double stigmatization on torture via the administration of dangerous electric shocks. While participants experienced significantly less personal distress and less other-oriented empathy for the doubly stigmatized victim than for the others victims, only other-oriented empathy was negatively and significantly related to the level of torture administrated to the victim (i.e. mean maximum voltage level).Thus, personal distress does not appear to play a causal role in the behavior of torture observed in this study. On the other hand, the less the participants experienced empathy for the victim, the more they punished it. Mediation analyses support the model in which empathy for the victim plays a mediating function in the causal relation between double stigmatization and torture. These results are consistent with recent social neuroscience research showing that empathy is affected very early in the information processing by the targets' stigmatization (e.g. Decety et al., 2009) and previous works showing that empathic resonance is not simply a reflection of a relatively automatic bottom-up process (Preston \& de Waal, 2002).

The present study also has some implications for the prevention of crimes of obedience. Recent research showed that ordinary soldiers became war criminal "through the use of basic recruitment and training strategies, general authorizations for increased aggression and violence (...), authorizations for more aggressive interrogations, a range of pressures and protections, and the dehumanization of [victims]" (Lankford, 2009: p. 388). Past violent systems have used similar strategies to motivate ordinary people to commit crimes of obedience (see Browning, 1998; Kelman \& Hamilton, 1989). Our results could help to construct several specific strategies to reform police and military training and prevent crimes of obedience in the future. Some authors proposed several ways to do this, such as to change the military's recruitment priorities and the basic training (see Lankford, 2009). In addition, we should reexamine the strategic dehumanization of targets that often takes place in context of violent conflicts, such as the implementation of the belief that the targets cannot experience complex human emotions. Empathic concern requires an effortful self-regulatory process to conscientiously engaging in perspective taking, maintaining conscious engagement in perspective taking, and maintenance of clear self-other distinction. Because such an effort involves the motivation to understand the targets' state, empathic responses towards stigmatized out-group members might be mediated by restoring the belief that out-group members can have complex human emotions (Leyens et al., 2001). Thus, in order to restore the sensitivity to the targets' pain, we should enhance the perspective taking abilities of those engage in conflicts using cognitive reappraisal training methods. Indeed, such methods have been demonstrated to enhance reconciliatory attitudes in intractable conflict (see Halperin, Porat, Tamir, \& Gross, 2013).

\subsection{Limitations of the Current Study and Future Directions}

The results of the present study do not perfectly match those of Dambrun and Vatiné (2010). For example, while Dambrun \& Vatiné (2010) reported a similar treatment of the North African and the French victim, in the present study, the mean maximum voltage level was higher when the victim was North African than when she 
was French or Spanish. A possible explanation is that these inconsistencies stem from the adaptation of the cover story by giving participants the social role of being part of the national security service. Such a social role could provide a normative context justifying a differential treatment of the racially stigmatized victim (i.e. North African). It may be interesting to include measures of perceived social roles and their perceived related norms in future studies to advance our understanding of normative conditions that favor or inhibit destructive obedience behaviors (see also De Oliveira, Guimond, \& Dambrun, 2012).

As previously noted, mediation analyses support the model where empathy plays a mediating function in the causal relation between double stigmatization and torture for the victim. However, it is important to note that this mediation was partial and that the reversed model also was adequate. According to the present findings, it is likely that low empathy for the victim increases the tendency to torture, but it is also likely that the behavior of torture decreases empathy for the victim, these two effects reinforcing each other. In our protocol, the measure of empathy was assessed at the end of the IVMOE-I, after the participants had administered the electric shocks. If empathy is the underlying process, i.e. the mediator, it should occur upstream of the behavior. The fact that we measured it at the end is a limitation. Therefore, it would be useful to replicate these results with real-time measurement.

\subsection{Conclusion}

Despite its social and societal importance, the empirical study of obedience crimes has been relatively neglected by the social sciences. The psychological processes leading to the torture of out-group members need to be examined scientifically. In the long term, such knowledge represents a relevant source for the prevention of such phenomena. The aim of the present study was to contribute to this perspective by demonstrating the importance of stigmatization and by examining its underlying processes.

The present study provides additional empirical support for the usefulness of immersive environment to study destructive obedience. We found that dehumanization play an important role in determining the ways in which authorities influence and guide the agents' behaviors to destructives ends by impairing other-oriented empathy. These results give empirical support to the idea that obedience is highly related to how individuals conceptualize both the situation and the victim, and do not only arise from a passive conformity to roles.

Finally, crimes of obedience are perpetrated in some very specific ideological contexts that remain to study. As noted by Bandura (1999), "people do not ordinarily engage in harmful conduct until they have justified to themselves the morality of their actions.” (p. 194). Because some ideologies have the potential to provide a moral justification for such extreme social behaviors, their role needs to be studied. We are currently working in this direction.

\section{References}

Bandura, A. (1999). Moral Disengagement in the Perpetration of Inhumanities. Personality and Social Psychology Review, 3 , 193-209. http://dx.doi.org/10.1207/s15327957pspr0303_3

Bar-Tal, D. (1989). Delegitimization: The Extreme Case of Stereotyping and Prejudice. In D. Bar-Tal, C. Graumann, A. W. Kruglanski, \& W. Stroebe (Eds.), Stereotyping and Prejudice: Changing Conceptions (pp. 169-188). New York: Springer. http://dx.doi.org/10.1007/978-1-4612-3582-8_8

Batson, C. D. (1991). The Altruism Question: Toward a Social-Psychological Answer. Hillsdale: Erlbaum Associates.

Batson, C. D., Batson, J. G., Singlsby, J. K., Harrell, K. L., Peekna, H. M., \& Todd, R. M. (1991). Empathic Joy and the Empathy-Altruism Hypothesis. Journal of Personality and Social Psychology, 61, 413-426.

http://dx.doi.org/10.1037/0022-3514.61.3.413

Baumeister, R. F. (1997). Evil: Inside Human Cruelty and Violence. New York: W. H. Freeman and Company.

Blascovich, J., Loomis, J., Beall, A., Swinth, K., Hoyt, C. \& Bailenson, J. N. (2002). Immersive Virtual Environment Technology as a Methodological Tool for Social Psychology. Psychological Inquiry, 13, 103-104. http://dx.doi.org/10.1207/S15327965PLI1302_01

Browning, C. R. (1998). Ordinary Men: Reserve Police Battalion 101 and the Final Solutionin Poland. New York: HarperCollins Publishers, Inc.

Burger, J. M. (2009). Replicating Milgram: Would People still Obey Today? American Psychologist, 64, 1-11. http://dx.doi.org/10.1037/a0010932

Chambon, M., Droit-Volet, S., \& Niedenthal, P. M. (2008). The effect of embodying the elderly on time perception. Journal of Experimental Social Psychology, 44, 672-678. http://dx.doi.org/10.1016/j.jesp.2007.04.014 
Cheetham, M., Pedroni, A. F., Angus, A., Slater, M., \& Jäncke, L. (2009). Virtual Milgram: Empathic Concern or Personal Distress? Evidence from Functional MRI and Dispositional Measures. Frontiers in Human Neuroscience, 3, 29. http://dx.doi.org/10.3389/neuro.09.029.2009

Dambrun, M. (2007). Understanding the Relationship between Racial Prejudice and Support for the Death Penalty: The Racist Punitive Bias Hypothesis. Social Justice Research, 20, 228-249. http://dx.doi.org/10.1007/s11211-007-0040-1

Dambrun, M., \& Vatiné, E. (2010). Reopening the Study of Extreme Social Behaviors: Obedience to Authority within an Immersive Video Environment. European Journal of Social Psychology, 40, 760-773.

Davis, M. H. (1983). Measuring Individual Differences in Empathy: Evidence for a Multidimensional Approach. Journal of Personality and Social Psychology, 44, 113-126. http://dx.doi.org/10.1037/0022-3514.44.1.113

Decety, J., \& Jackson, P. L. (2004). The Functional Architecture of Human Empathy. Behavioral and Cognitive Neuroscience Reviews, 3, 71-100. http://dx.doi.org/10.1177/1534582304267187

Decety, J., \& Lamm, C. (2009). The Biological Basis of Empathy. In J. T. Cacioppo, \& G. G. Bernston (Eds.), Handbook of Neuroscience for the Behavioral Sciences. New York: John Wiley and Sons.

Decety, J., Echols, S., \& Correll, J. (2010). The Blame Game: The Effect of Responsibility and Social Stigma on Empathy for Pain. Journal of Cognitive Neuroscience, 22, 985-997.

http://dx.doi.org/10.1162/jocn.2009.21266

De Oliveira, P., Guimond, S., \& Dambrun, M. (2012). Power and Legitimizing Ideologies in Hierarchy-Enhancing vs. Hierarchy Attenuating Environments. Political Psychology, 33, 867-885. http://dx.doi.org/10.1111/j.1467-9221.2012.00909.x

Echebarria-Echabe, A., \& Fernández-Guede, E. (2006). Effects of Terrorism on Attitudes and Ideological Orientation. European Journal of Social Psychology, 36, 259-265. http://dx.doi.org/10.1002/ejsp.294

Elfenbein, H. A., \& Ambady, N. (2002). Is There an In-Group Advantage in Emotion Recognition? Psychological Bulletin, 128, 243-249. http://dx.doi.org/10.1037/0033-2909.128.2.243

Eisenberg, N., \& Eggum, N. D. (2009). Empathic Responding: Sympathy and Personal Distress. In J. Decety, \& W. Ickes (Eds.), The Social Neuroscience of Empathy (pp. 71-83). Cambridge, MA: MIT Press.

Eisenberg, N., Valiente, C., \& Champion, C. (2004). Empathy-Related Responding: Moral, Social, and Socialization Correlates. In A. G. Miller (Ed.), The Social Psychology of Good and Evil: Understanding Our Capacity for Kindness and Cruelty (pp. 386-415). New York: Guilford Press.

Fiske, S. T., Cuddy, A. J., Glick, P., \& Xu, J. (2002). A Model of (Often Mixed) Stereotype Content: Competence and Warmth Respectively Follow from Perceived Status and Competition. Journal of Personality and Social Psychology, 82, 878-902. http://dx.doi.org/10.1037/0022-3514.82.6.878

Fiske, S. T., Harris, L. T., \& Cuddy, A. J. C. (2004). Why Ordinary People Torture Enemy Prisoners. Science, 306, 14821483. http://dx.doi.org/10.1126/science.1103788

Greenwood, J. D. (1989). Explanation and Experiment in Social Psychological Science. Realism and the Social Constitution of Action. New York: Springer-Verlag. http://dx.doi.org/10.1007/978-1-4613-8801-2

Guimond, S. (2010). Psychologie Sociale: Perspective Multiculturelle. Wavre: Mardaga.

Halperin, E., Porat, R., Tamir, M., \& Gross, J. J. (2013). Can Emotion Regulation Change Political Attitudes in Intractable Conflicts? From the Laboratory to the Field. Psychological Science, 24, 106-111. http://dx.doi.org/10.1177/0956797612452572

Harris, L. T., \& Fiske, S. T. (2006). Dehumanizing the Lowest of the Low: Neuroimaging Responses to Extreme Out-Groups. Psychological Science, 17, 847-853. http://dx.doi.org/10.1111/j.1467-9280.2006.01793.x

Hitlan, R. T., Carrillo, K., Zárate, M. A., \& Aikman, S. N. (2007). Attitudes toward Immigrant Groups and the Effects of the September 11 Terrorist Attacks. Peace and Conflict: Journal of Peace Psychology, 13, 135-152. http://dx.doi.org/10.1080/10781910701270970

Johnson, R. (1986). Institutions and the Promotion of Violence. In A. Campbell, \& J. J. Gibbs (Eds.), Violent Transactions: The Limits of Personality (pp. 181-205). Oxford: BasilBlackwell.

Johnson, R. (1998). Death Work: A Study of the Modern Execution Process. Belmont, CA: Wadsworth Publishing Company.

Kelman, H. C. (2001). Reflections on the Social and Psychological Processes of Legitimization and Delegitimization. In J. T. Jost, \& B. Major (Eds.), The Psychology of Legitimacy: Emerging Perspectives on Ideology, Justice, and Intergroup Relations (pp. 54-73). Cambridge: Cambridge University Press.

Kelman, H. C. (2005). The Policy Context of Torture: A Social-Psychological Analysis. International Review of the Red Cross, 87, 123-134. http://dx.doi.org/10.1017/S1816383100181214 
Kelman, H. C., \& Hamilton, V. (1989). Crimes of Obedience: Toward a Social Psychology of Authority and Responsibility. New Haven, CT: Yale University Press.

Lankford, A. (2009). Promoting Aggression and Violence at Abu Ghraib: The US Military’s Transformation of Ordinary People into Torturers. Aggression and Violent Behavior, 14, 388-395. http://dx.doi.org/10.1016/j.avb.2009.06.007

Leyens, J. P., Cortes, B. P., Demoulin, S., Dovidio, J., Fiske, S. T., Gaunt, R., Paladino, M. R., Rodriguez-Perez, A., Rodriguez-Torres, R., \& Vaes, V. (2003). Emotional Prejudice, Essentialism, and Nationalism. The 2002 Tajfel Lecture. European Journal of Social Psychology, 33, 703-717. http://dx.doi.org/10.1002/ejsp.170

Leyens, J. R., Rodriguez-Perez, A., Rodriguez-Torres, R., Gaunt, R., Paladino, M. R., Vaes, J., \& Demoulin, S. (2001). Psychological Essentialism and the Differential Attribution of Uniquely Human Emotions to In-Groups and Out-Groups. European Journal of Social Psychology, 31, 395-411. http://dx.doi.org/10.1002/ejsp.50

Milgram, S. (1974). Obedience to Authority: An Experimental View. New York: Harper \& Row.

Mondillon, L., Niedenthal, P. M., Gil, S., \& Droit-Volet, S. (2007). Imitation of In-Group versus Out-Group Members’ Facial Expressions of Anger: A Test with a Time Perception Task Result. Social Neuroscience, 2, 223-237. http://dx.doi.org/10.1080/17470910701376894

Niedenthal, P. M. (2007). Embodying Emotion. Science, 316, 1002-1005. http://dx.doi.org/10.1126/science.1136930

Opotow, S. (1990). Moral Exclusion and Injustice: An Introduction. Journal of Social Issues, 46, 1-20. http://dx.doi.org/10.1111/j.1540-4560.1990.tb00268.x

Oren, N., \& Bar-Tal, D. (2006). The Detrimental Dynamics of Delegitimization in Intractable Conflicts: The Israeli-Palestinian Case. International Journal of Intercultural Relations, 31, 111-126. http://dx.doi.org/10.1016/j.ijintrel.2006.07.003

Osborne, J. W., \& Overbay, A. (2004). The Power of Outliers (and Why Researchers Should Always Check for Them). Practical Assessment, Research \& Evaluation, 9. http://PAREonline.net/getvn.asp?v=9\&n=6

Pettigrew, T. F., \& Tropp, L. R. (2008). How Does Intergroup Contact Reduce Prejudice? Meta-Analytic Test of Three Mediators. European Journal of Social Psychology, 38, 922-934. http://dx.doi.org/10.1002/ejsp.504

Preacher, K. J., \& Hayes, A. F. (2004). SPSS and SAS Procedures for Estimating Indirect Effects in Simple Mediation Models. Behavior Research Methods, Instruments, \& Computers, 36, 717-731. http://dx.doi.org/10.3758/BF03206553

Preston, S. D., \& de Waal, F. B. M. (2002). Empathy: Its Ultimate and Proximate Bases. Behavioral and Brain Sciences, 25, $1-72$.

Schechtman, Z., \& Basheer, O. (2005). Normative Beliefs Supporting Aggression of Arab Children in an Intergroup Conflict. Aggressive Behavior, 31, 324-335. http://dx.doi.org/10.1002/ab.20069

Slater, M., Antley, A., Davison, A., Swapp, D., Guger, C., Barker, C., Pistrang, N., \& Sanchez-Vives, M. V. (2006). A Virtual Reprise of the Stanley Milgram Obedience Experiments. PLOS ONE, 1, 1-10. http://dx.doi.org/10.1371/journal.pone.0000039

Spielberger, C. D., Gorsuch, R. L., \& Luchene, R. E. (1970). Manual for State-Trait Anxiety Inventory. Palo Alto, CA: Consulting Psychologists Press.

Waller, J. (2002). Becoming Evil: How Ordinary People Commit Genocide and Mass Killing. Oxford: Oxford University Press.

Wheeler, M. E., \& Fiske, S. T. (2005). Controlling Racial Prejudice: Social-Cognitive Goals Affect Amygdala and Stereotype Activation. Psychological Science, 16, 56-63. http://dx.doi.org/10.1111/j.0956-7976.2005.00780.x

Xu, X., Zuo, X., Wang, X., \& Han, S. (2009). Do You Feel My Pain? Racial Group Membership Modulates Empathic Neural Responses. The Journal of Neuroscience, 29, 8525-8529. http://dx.doi.org/10.1523/JNEUROSCI.2418-09.2009 
Scientific Research Publishing (SCIRP) is one of the largest Open Access journal publishers. It is currently publishing more than 200 open access, online, peer-reviewed journals covering a wide range of academic disciplines. SCIRP serves the worldwide academic communities and contributes to the progress and application of science with its publication.

Other selected journals from SCIRP are listed as below. Submit your manuscript to us via either submit@scirp.org or Online Submission Portal.
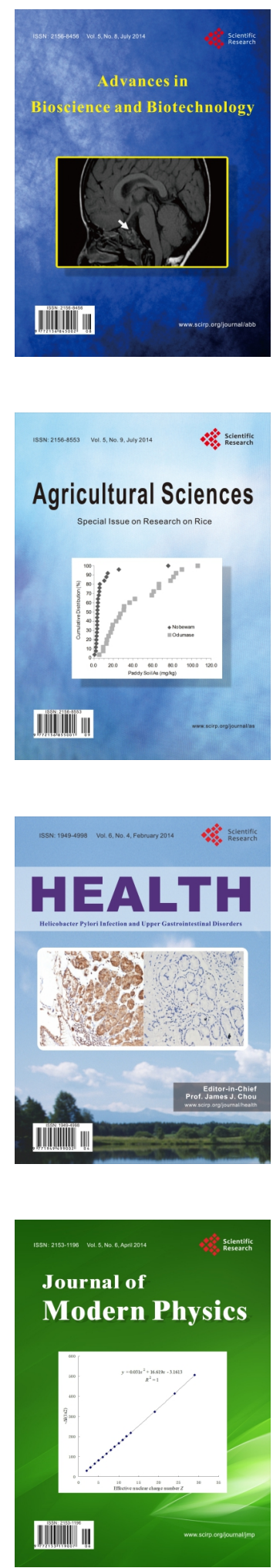
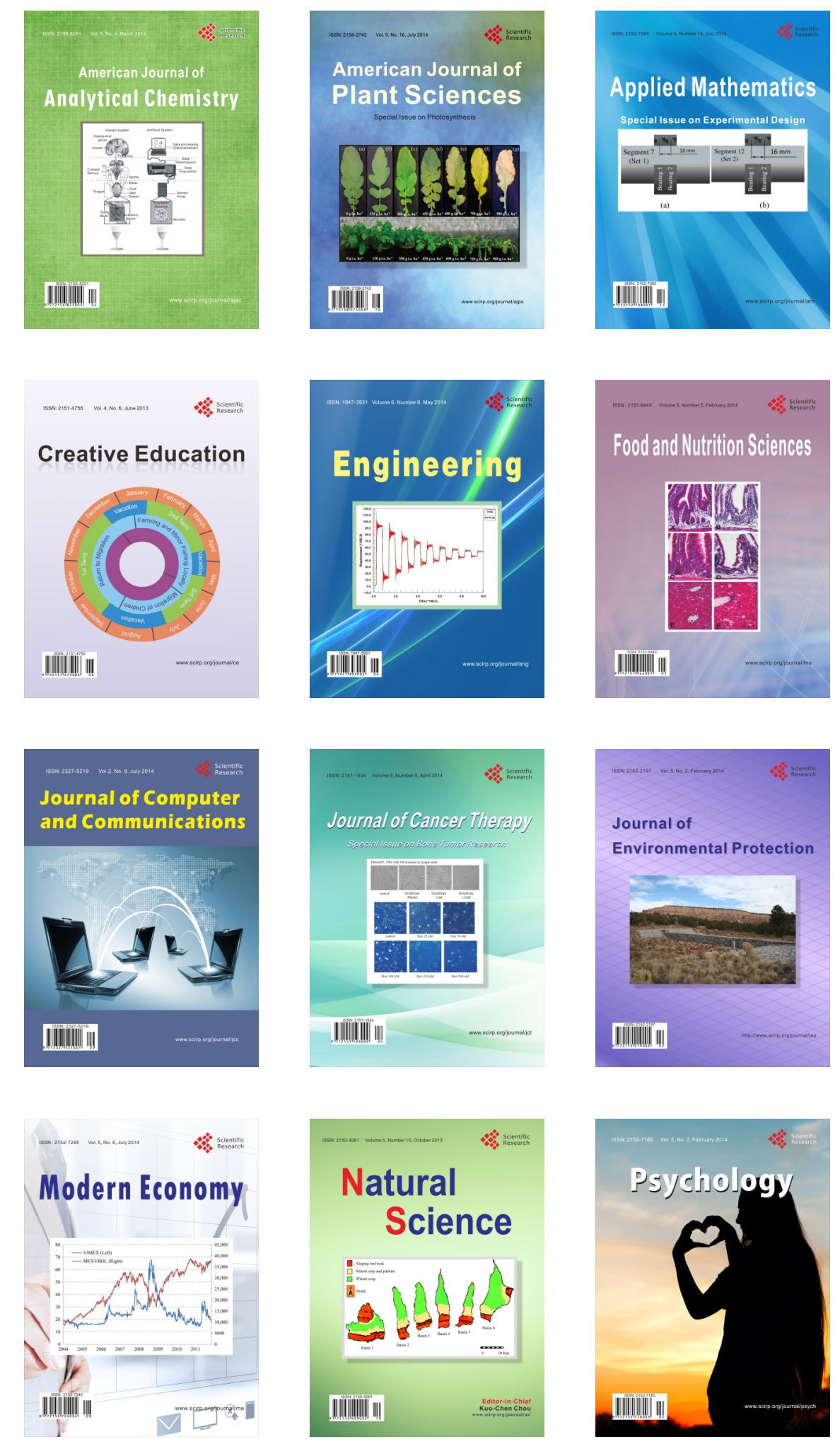